\title{
زخارف ونقوش معبد نيرون() في أكوريس (طهنا الجبل )
}

د/ محمد فخري عبد الجليل

مفنش بوزارة الآثار

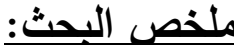

يتتـاول البحث الزخارف والنقوش الخاصـة بمعبد نيرون الذي يقع في مدينة أكوريس وتحديداً بالجزء الجنوبي الغربي من المدينة الأثرية ( أكوريس ) والإمبراطور نبرون لم يكن صاحب لئب اللبنة

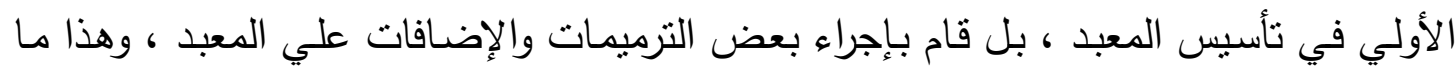
ظهر بوضوح من خلال دراسة النقوش والزخارف الموجودة بالمعبد .

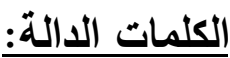

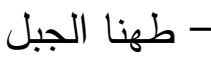

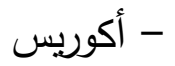

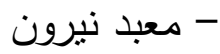

- بقايا معابد رمسيس الثاني بمنطقة المنيا

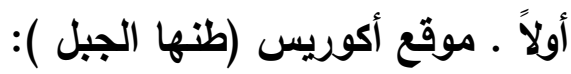

تقع أكوريس علي بعد حوالي • بr كم جنوب القاهرة علي الضفة الثرقية للنيل ، علي بعد

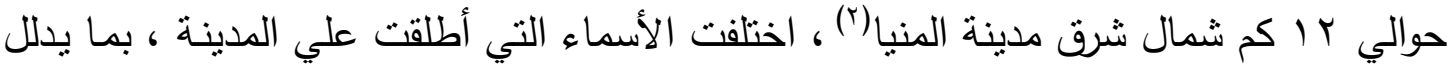
علي أهية موقع المدينة وزيادة نشاطها عبر العصور (").

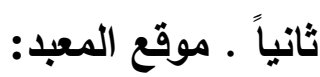

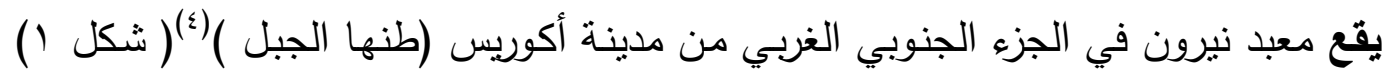
وهو مُقام علي تلَّ مرتفع عن مستوي مياه نهر النيل علي أنقاض معبد قديم ، ويدلل علي ذللك الكئل

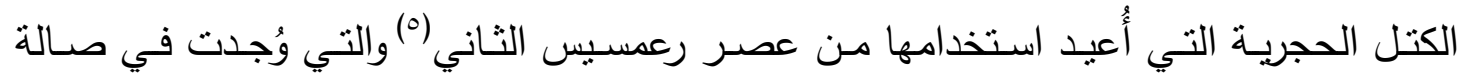

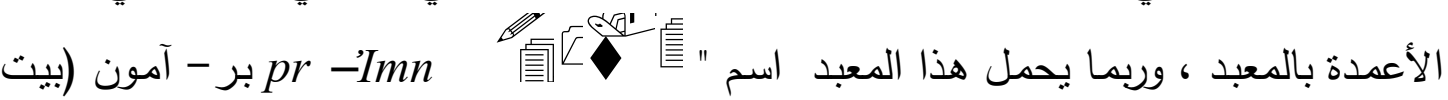

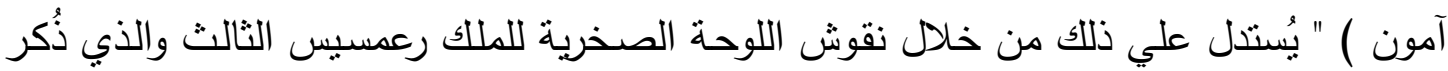
فيها اسم مدينة أكوريس خلال عصر الدولة الحديثة Pr-imn-m3i-hnt (بيت آمون - الأسد

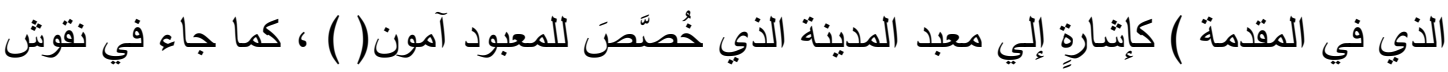

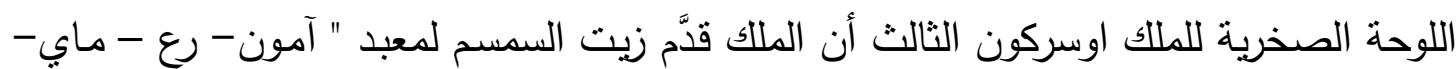
خنت " بالمدينة (†). ثالثاً . وصف المعبد : بالمدينة يمتـــ محور هذا المعبد مـن الثنمال إلـي الجنوب ويتبع بـذلك التخطيط العـام للمعبد المصري في العصرين البطلمي والروماني ، إلا أن هذا المعبد ذو طراز فريد ، حيث نُجِتَّن نصفه

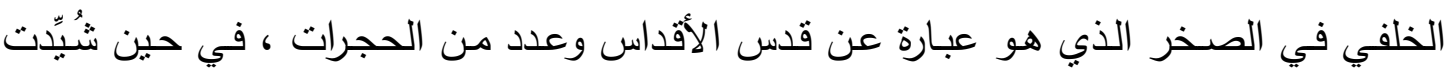


صالة الأعمدة والفناء الأمامي من الأحجار أمام الصخرة العالية ، ويصل إلي المعبد من خلال

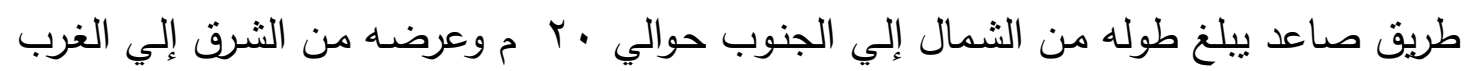

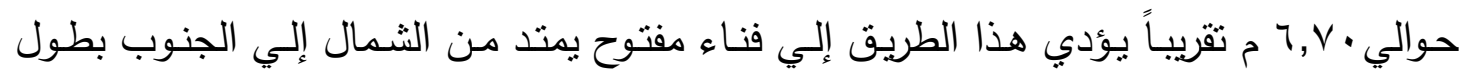

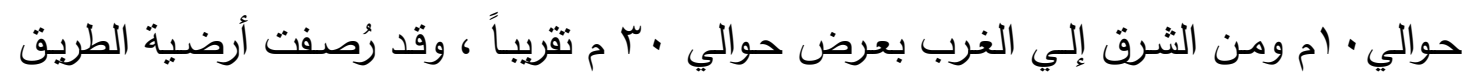

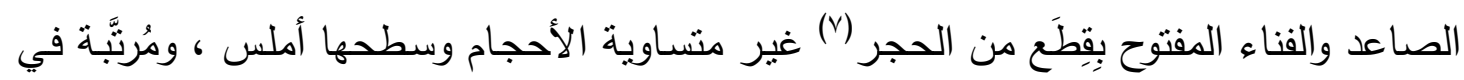

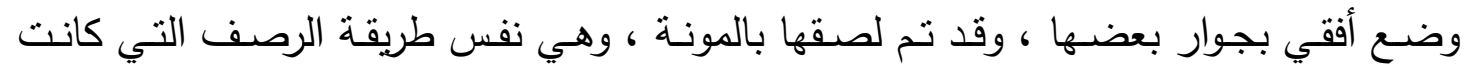

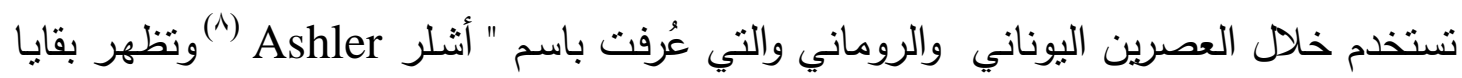

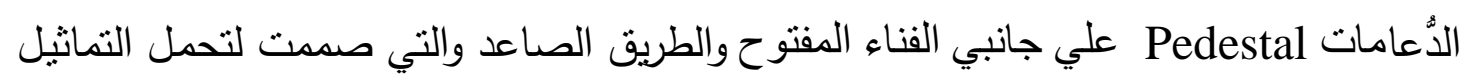

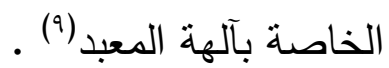

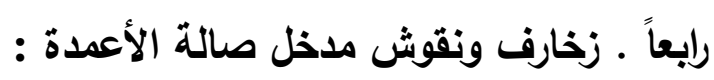
يتوسط الفناء المفتوح مدخل ضخم يؤدي إلي صالة الأعمدة ،مزخرف من الجانبين بحلية

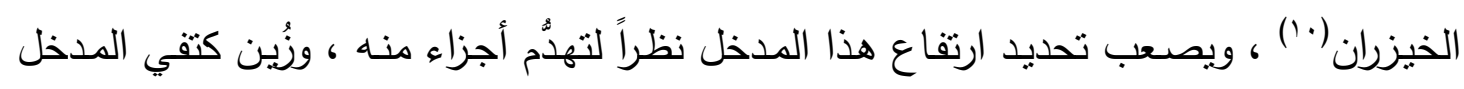

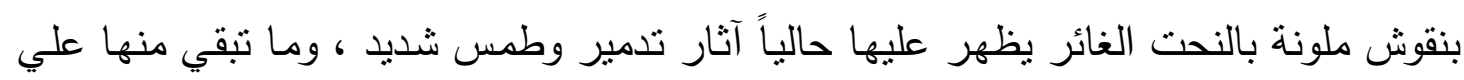

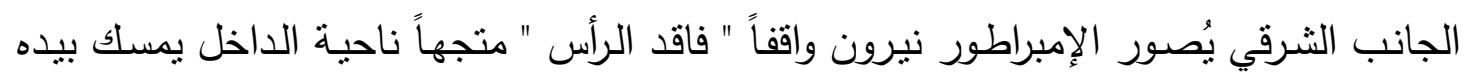

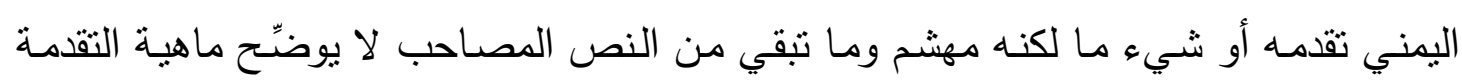

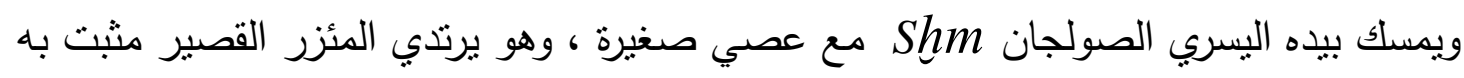

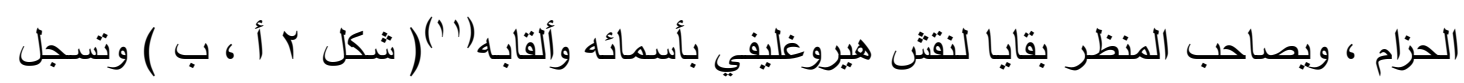

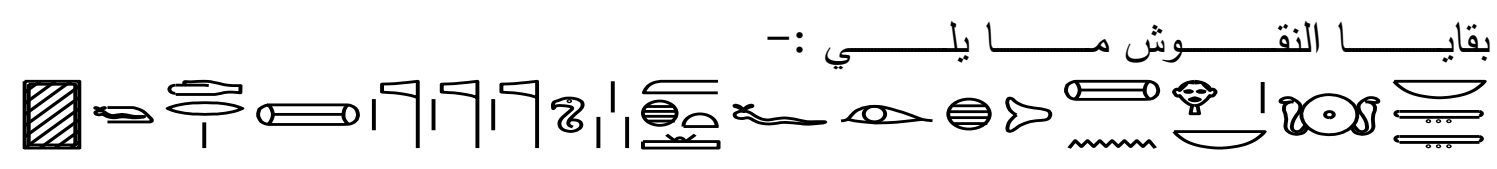

$(\underset{\text { man }}{\operatorname{man}})$

Pri dr mr ntrw rmt $m$ ht .f ir h్ $m r n$ hr $n b$ nsw bity $n b$ t3wy Nerun

الخارج بقوة ومعه أثياءه , محبوب الآلهة والبشر , محبوب الكل ملك مصر العليا والسفلى سيل الأرضيين نيرون(')

"خلف الإمبراطور"

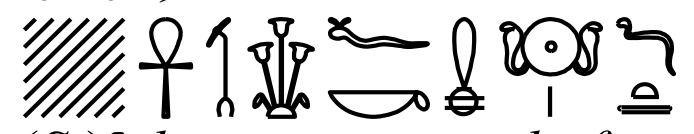

$(S 3)^{\complement} n h$ $w 3 s$ h?.f $n b$ mi $\quad r^{r}$ $\underline{d} t$ (كل) الحماية والحياة والسلطان خلفه منل رع للأبد . 


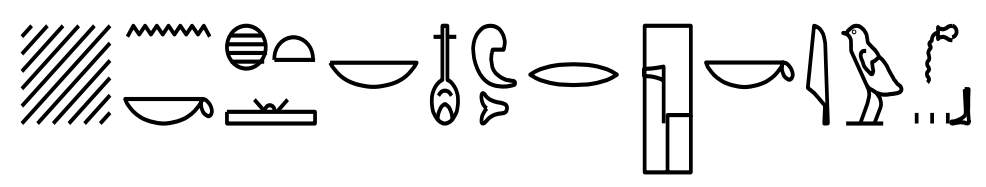

" الإمبراطور "

(di.i)n.k ht nb nfr r Hwt.k iw b

(قدم) للك كل شيء جميل إلى معبدك الطاهر م

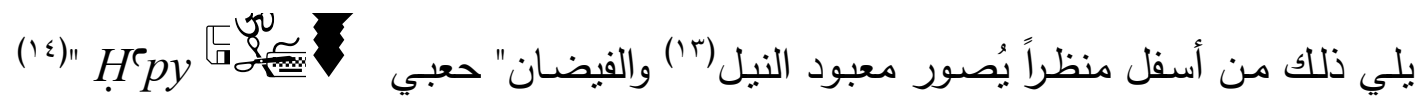

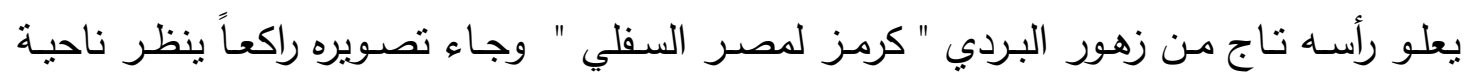

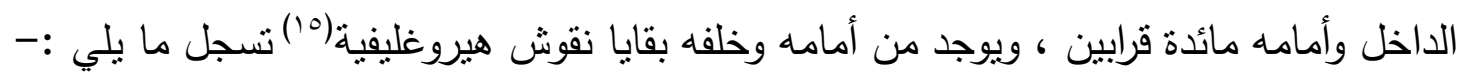

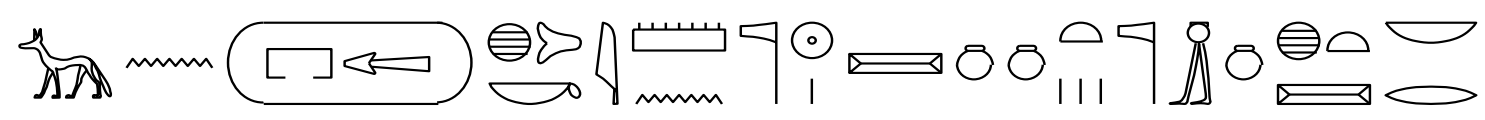
$\exists \rightarrow 002$

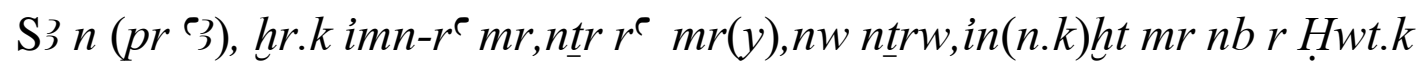
mi $r^{e} \underline{d} t$.

ابن البيت العظيم أمامك آمون رع محبوب الإله رع ومحبوب الآلهة , لقد أحضرت (لك) كل شي تحبه إلى معبدك منل رع للأبد.

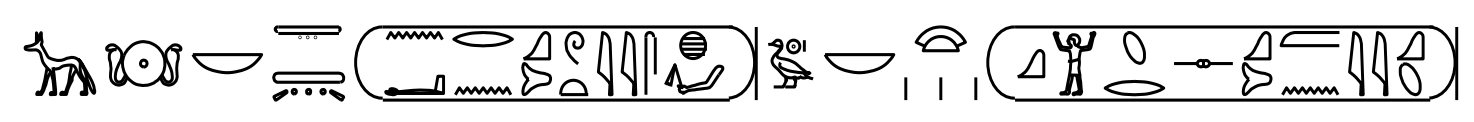

$\mathrm{S} 3 r^{\ulcorner} n b$ t3wy Nerun-kluts-kisirs h్ $w, \mathrm{~S} 3 r^{\ulcorner} n b h^{\complement} w$ kisirs kermenikes

$$
\begin{aligned}
& \text { ابـن الثـمس سيد الأرضيين " نيرون كلاوديوس الحـامي " ، ابـن الثـمس سيد الإنشراق }
\end{aligned}
$$

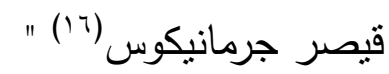

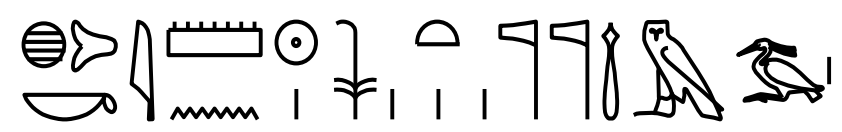

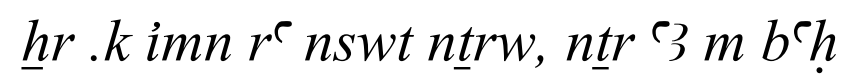

في حضرتلك آمون ر ع ملك الآلهة , الإله العظيم في الفيضان . 
زيُِّن الجانب الغربي من المدخل بنفس المنظر الموجود علي الجانب الشرقي ، لكنه دُّر (Yv) ، وما تبقي منه يوضح النصف السفلي من الإمبراطور نيرون ، واستثل علي ذلك من خلال بقايا

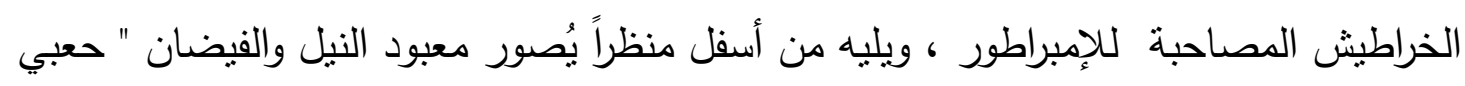
" ويعلو رأسـه تاج من زهور اللوتس " كرمز لمصر العلياوجاء تصويره ممـاثلاً لتصويره علي الجانب الثرقي ومن أمامه وخلفه بقايا نقوش هيروغليفية(^') تسجل ما يلي :-

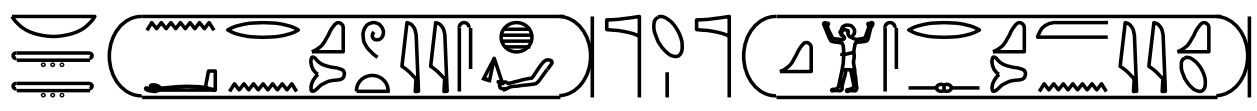

Nb t3wy-Nerun-kluts-kisirs ḩw - S3 ntr kisirs -kermenikes

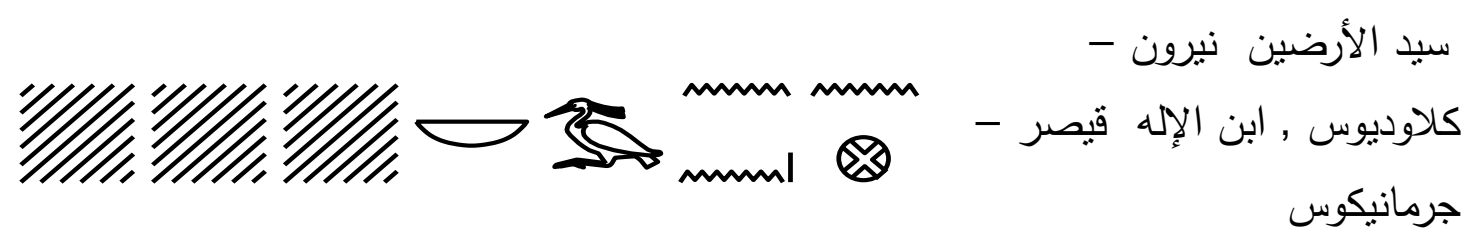

( ........... $) n b b^{\top} h$ n niwt

(19) سبد مدينة الفيضان (..........)

العتب العلوي لهذا المدخل مُهَشَّمَ وملقي علي الأرض (·+) ، وزُين هذا العتب من الخارج والداخل بمناظر تمنل الإمبراطور نيرون يقدم القرابين للمعبودات المصرية ، فيوجد من الخارج تمثيل

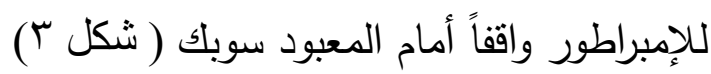

وصف المنظر :

المنظر يمثنل من أقصـي اليمين الإمبراطور نيرون واقفاً يعلو رأسـه تاج مركب علي هيئة

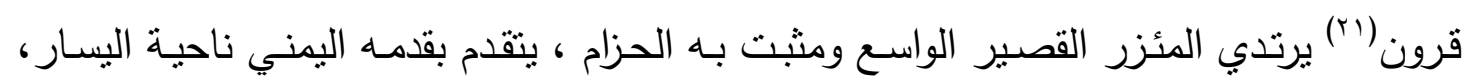
يحمل بيده اليسري علامة الحكم المذبة " >hhw " بينما يقدم بيده اليمني باقات من زهور اللوتس والبردي يتقدمه مباشرةً تصوير أخر للإمبراطور (r؟) وهو يتسلَّم رمز الحياة والقوة المتمثل بلئل

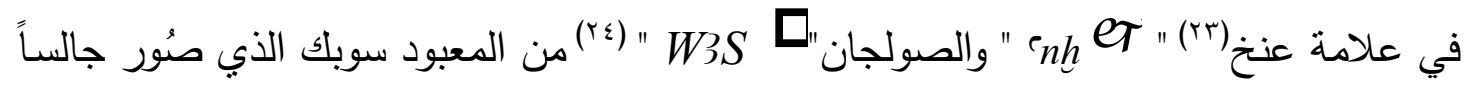
علي العرش ذو مسند الظهر القصير الذي يرتفع فوق قاعدة عريضـة وصسور - سوبك - في

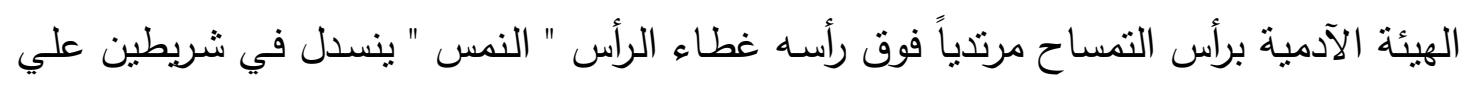
صدره ، يمسك بيده اليمني الصولجان " [ واس " بينما تقبض يده اليسري علي رمز الحياة " كَhe e " ، وخلفه نجد تمثيل آخر للمعبود سوبك في الهيئة الحيوانية برأس الصقر حورس رابطاً 


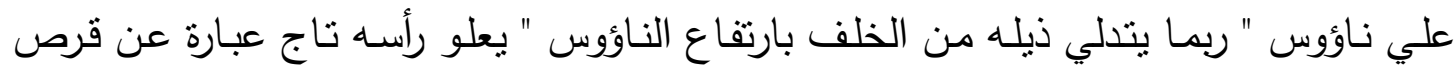

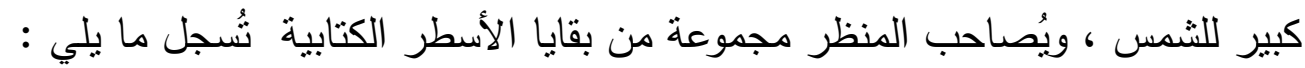

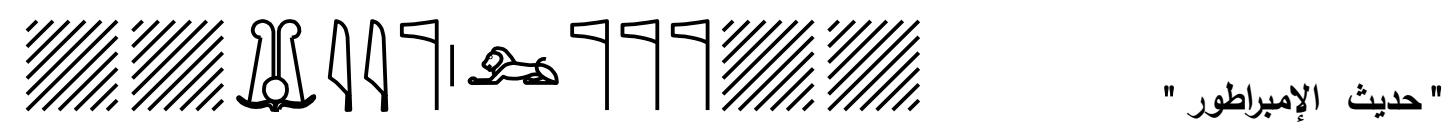

..$\check{w} w t y n t r \quad n b n t r w \ldots \ldots \ldots$

صاحب الريشتين سيد الآلهة (ro...........

"حديث سويك "

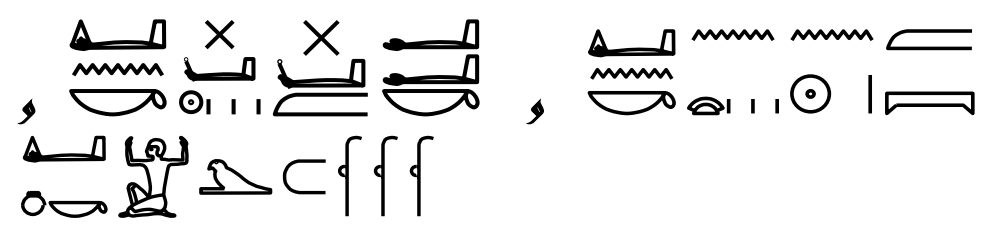

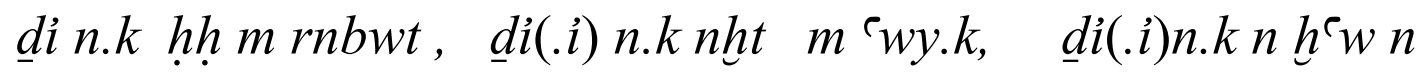
$r^{\top} m p t$

أمنحك ملايين السنين ، أمنحك القوة (الطاقة ) في يديك ، أمنحك التيجـان مثل رع في

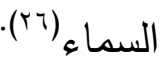

العتب العلوي الداخلي :

زُين العتب العلوي الداخلي بمنظر يمثل الإمبراطور يقوم بتقديم صناديق النسيج الأربعة

والتي تعرف باسم "صناديق المريت Mrt ( شكل - §) حيث صُور في المنتصف الإمبراطور نيرون واقفاً ينظر ناحية اليسار يعلوه رأسه

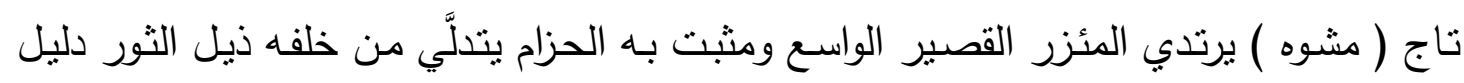

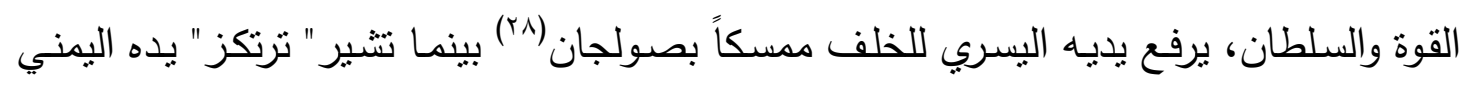

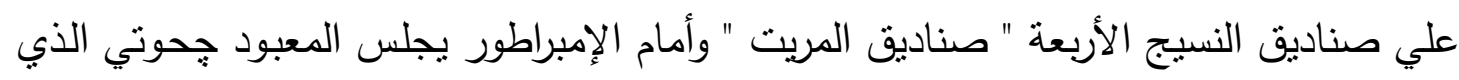

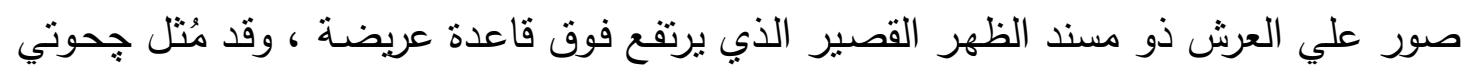

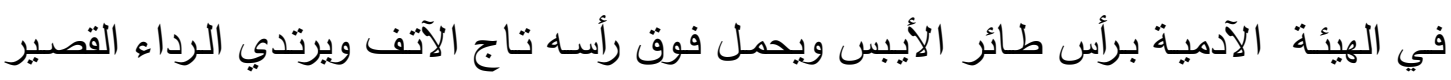

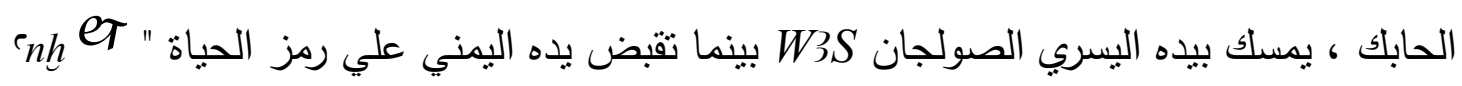

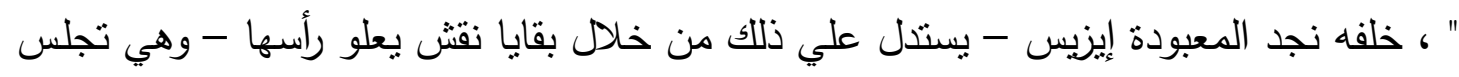
أيضا علي عرش ذو مسند ظهر قصير فوق قاعدة عريضة مرتفعة ويبدو أنها نرتدي فوق رأسها

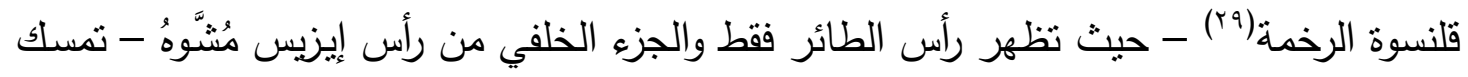




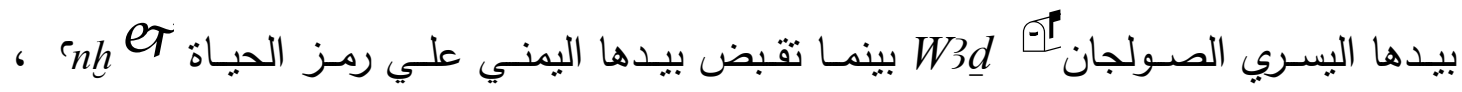
يصاحب المنظر بقايا أسطر كتابية تسجل ما يلي :-

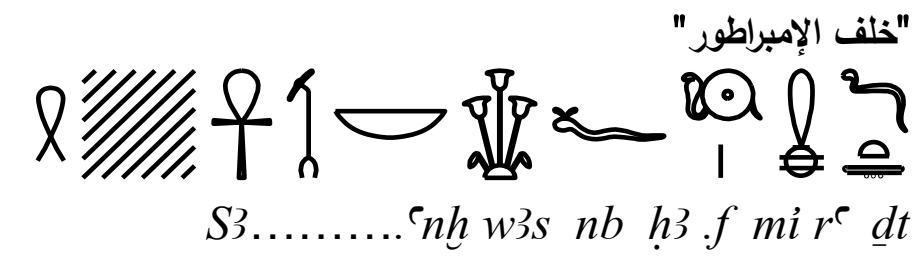
كل الحماية ...........الحياة والسلطة خلفه منل رع للأبد

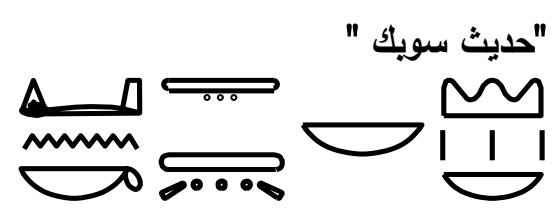
dil.ỉ) $n . k t 3 w y n b \underline{h} 3 s w t n b$

أمنحك الأرضين(·r) وكل البلاد الأجنبية(r)

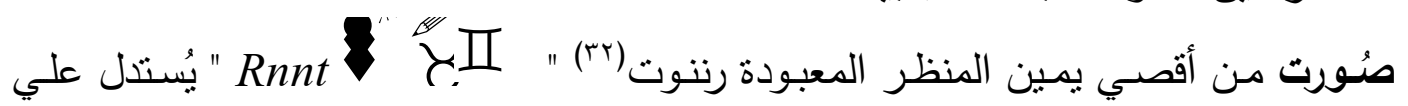
ذلك من خلال النص المصاحب لها ، جاء تصويرها وهي تجلس علي عرش ذو مسند ظهر قصير فوق قاعدة عريضـة مرتفعـة ، وترتدي فوق رأسـها قلنسـوة الرخمة ، تمسلك بيدها اليسري

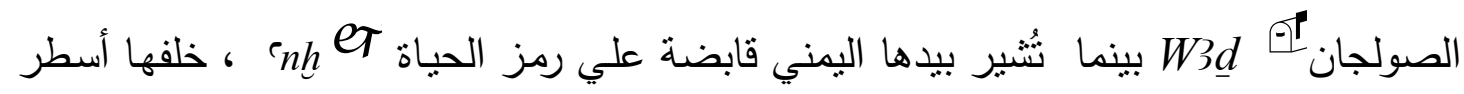

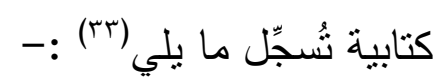

\section{H ........ntr ? Rnnt .,ir n.f.i nsw bity $n b$ t3wy}

[تحيا] رننوت الإلهة العظيمة (التي ) اعتتت بى وجعلنتي (مثل) رع سيد الأرضين(عَ)

HH/, I I .........dt Wisr hnt imntt ntr \& $n b \mathrm{mr}$ Mr-nfrt

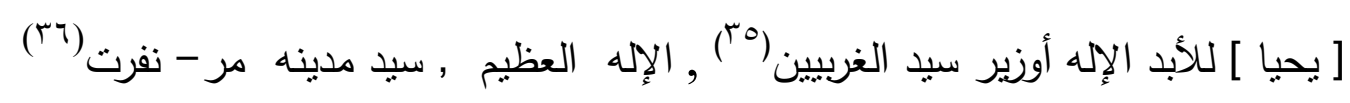


يُستدل من خلال الترجمة السابقة أن يكون الجزء المفقود من المنظر يصور المعبود أوزير يجلس علي العرش ذو مسند الظهر القصبر الذي يرتفع علي قاعدة عريضـة وذلك إلي جوار

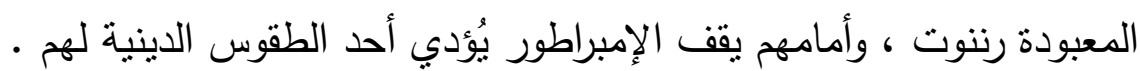

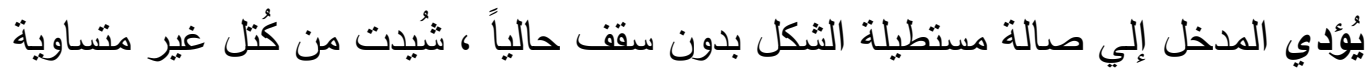

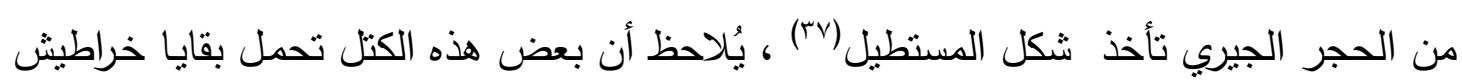

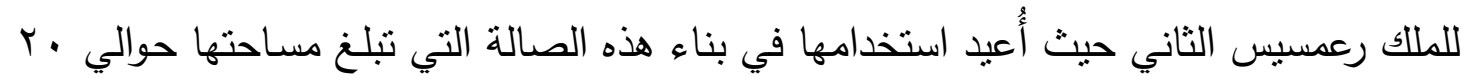

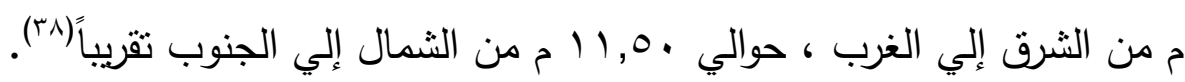
خامساً .زخارف ونقوش مدخل الحجرات الداخلية:

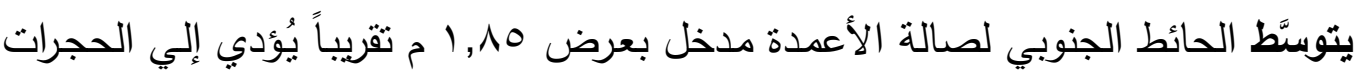

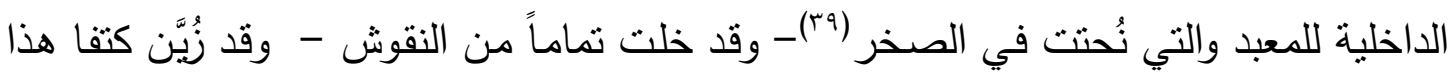
المدخل بنقش بارز تظهر عليه حالياً آثار تدمير وطمس شديد ، فقد صُور علي الكتف الأيسر

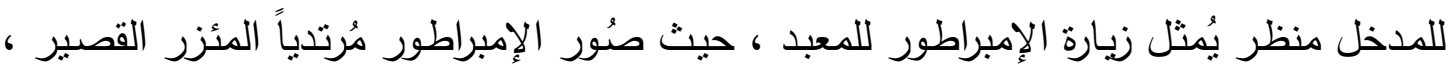

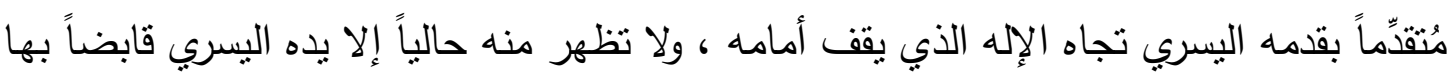

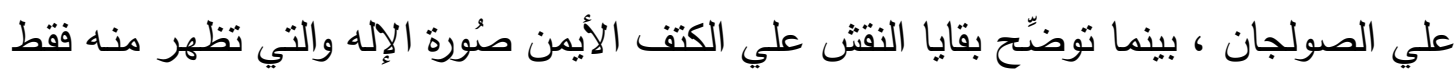

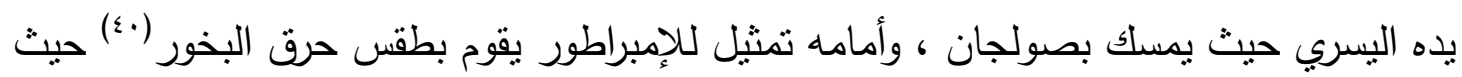

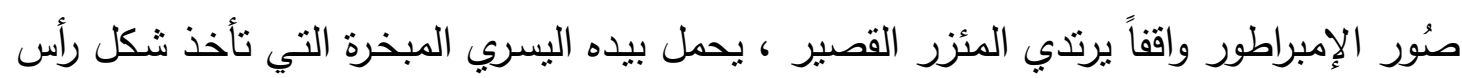

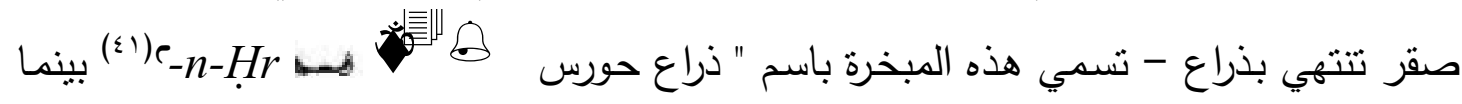

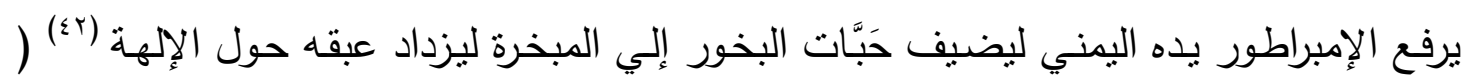

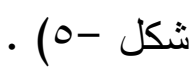
جدير بالذكر أن هذا المعبد ظل مزدهراً وتُؤدي فيه الطقوس والثعائر الدينية حتى أوائل

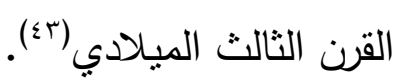

\section{اللدارسة التحليلية}

- يتضـح من خـلال دراسـة النقوش أن الإمبراطور نيرون لم يكون صـاحب اللَّبَنَة الأولي في

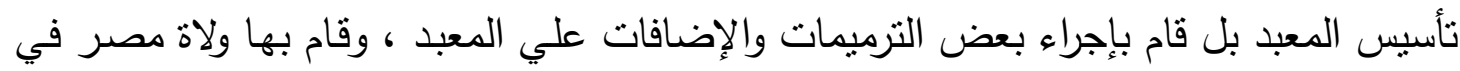

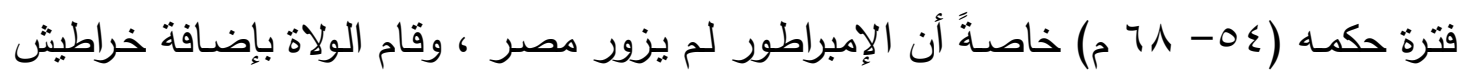

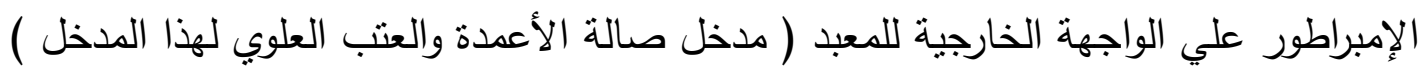
- يُلاحظ وجود تتاسق فني في جميع المناظر علي العتب العلوي للمدخل، فقد صَوَّر الفنان

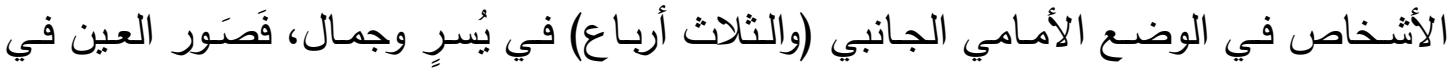




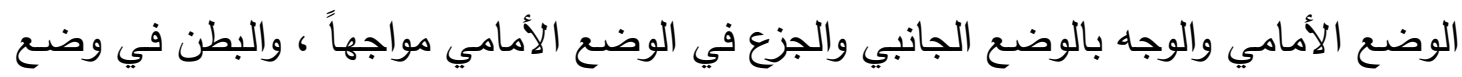

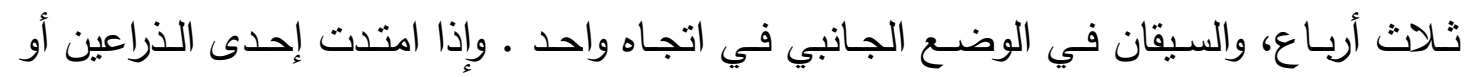

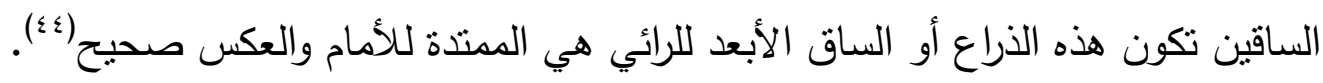

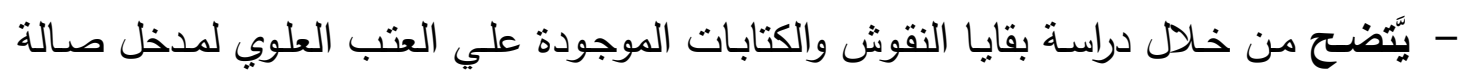

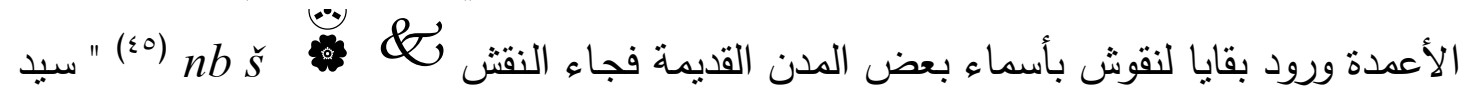

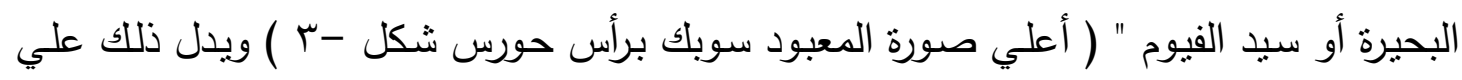

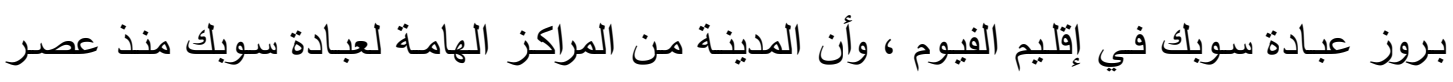

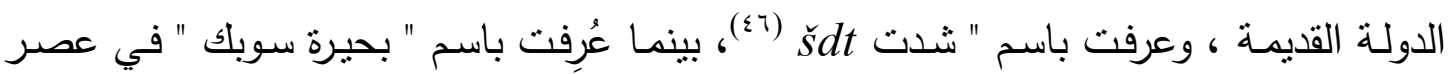

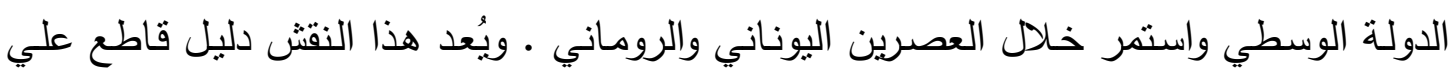

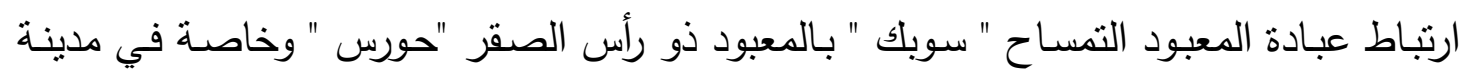

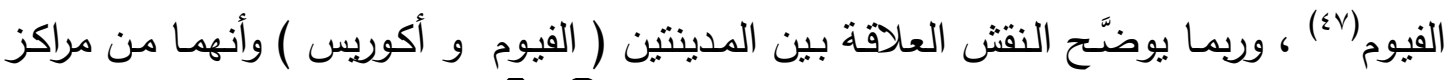

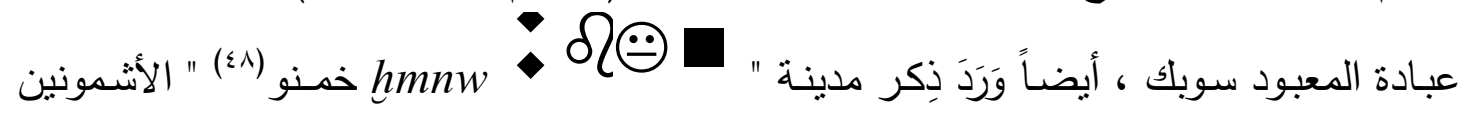
(أعلي صورة المعبود جحوتي شكل- ؛ ) ويدل ذللك علي الترابط الوثيق بين المعبود جحوتي دئي وبين مدينة خمنو التي تُعد من أهم مراكز عبادة .

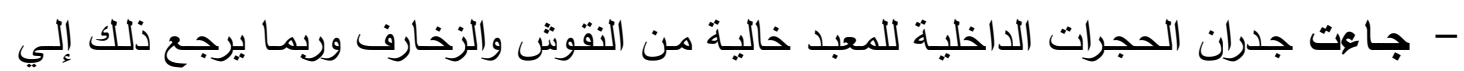
ضعف الحالة الاقتصادية التي كانت عليها البلاد خلاد تلك الفترة مما أنَّر علي موارد الأقاليم المصرية والتي تحوَّلت لخدمة روما ، وربما يرجع ذللك إلي ضعف الفن الإقليمي في تلك الفترة

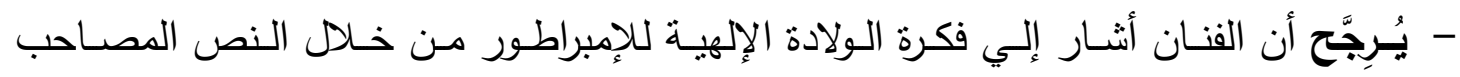

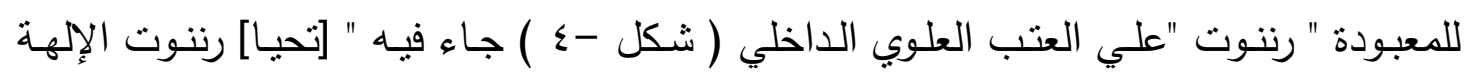

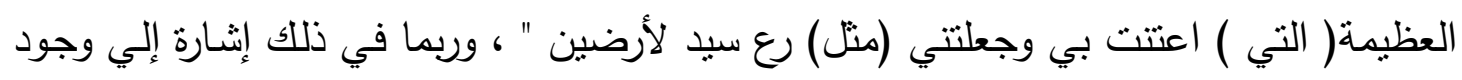

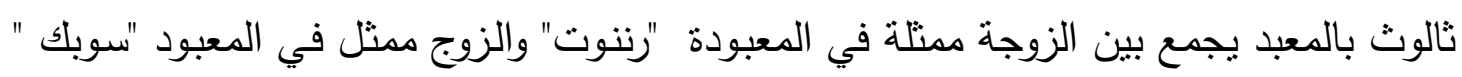

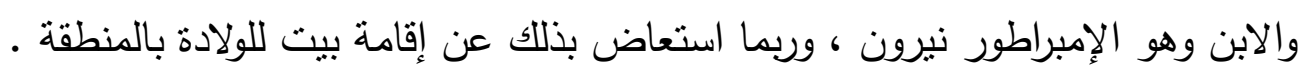

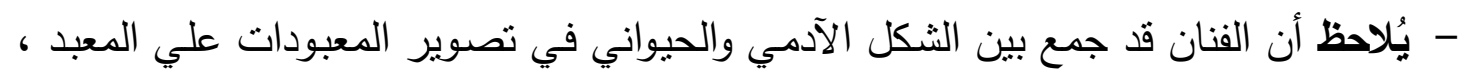

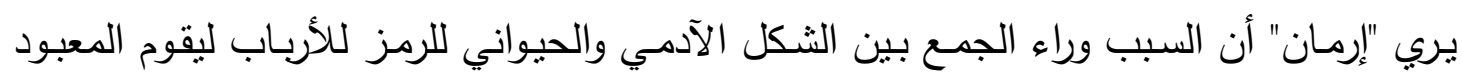

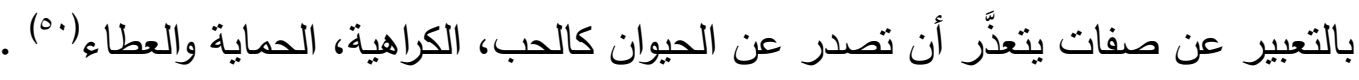




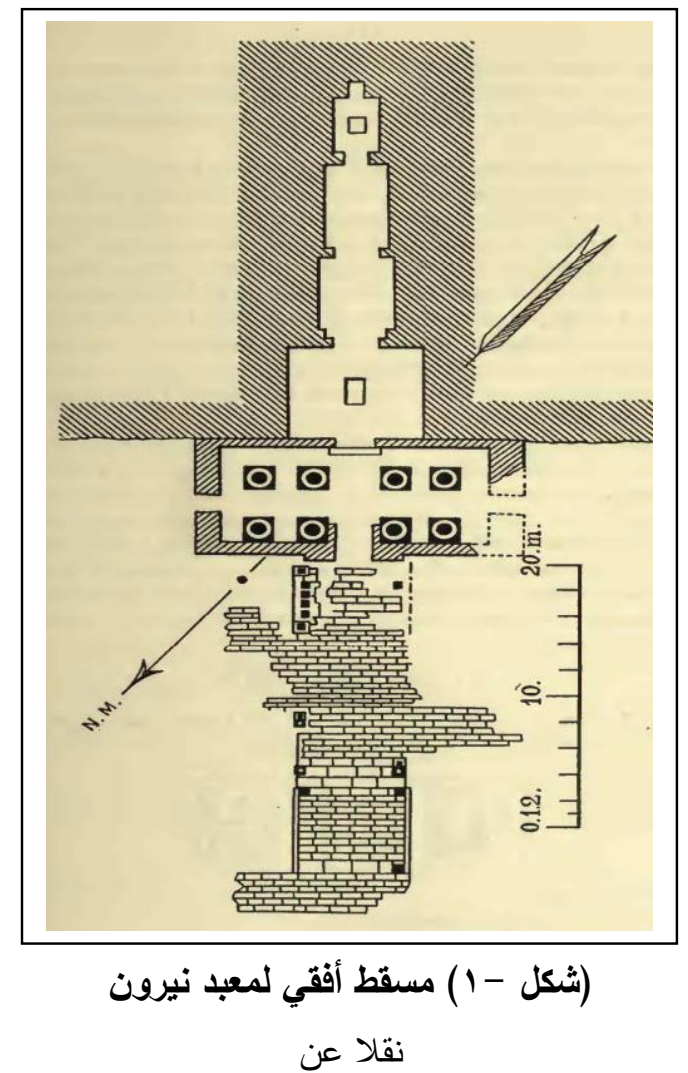

Lefebvre (G.)\& Barry (L.), ASAE .6,Fig.1

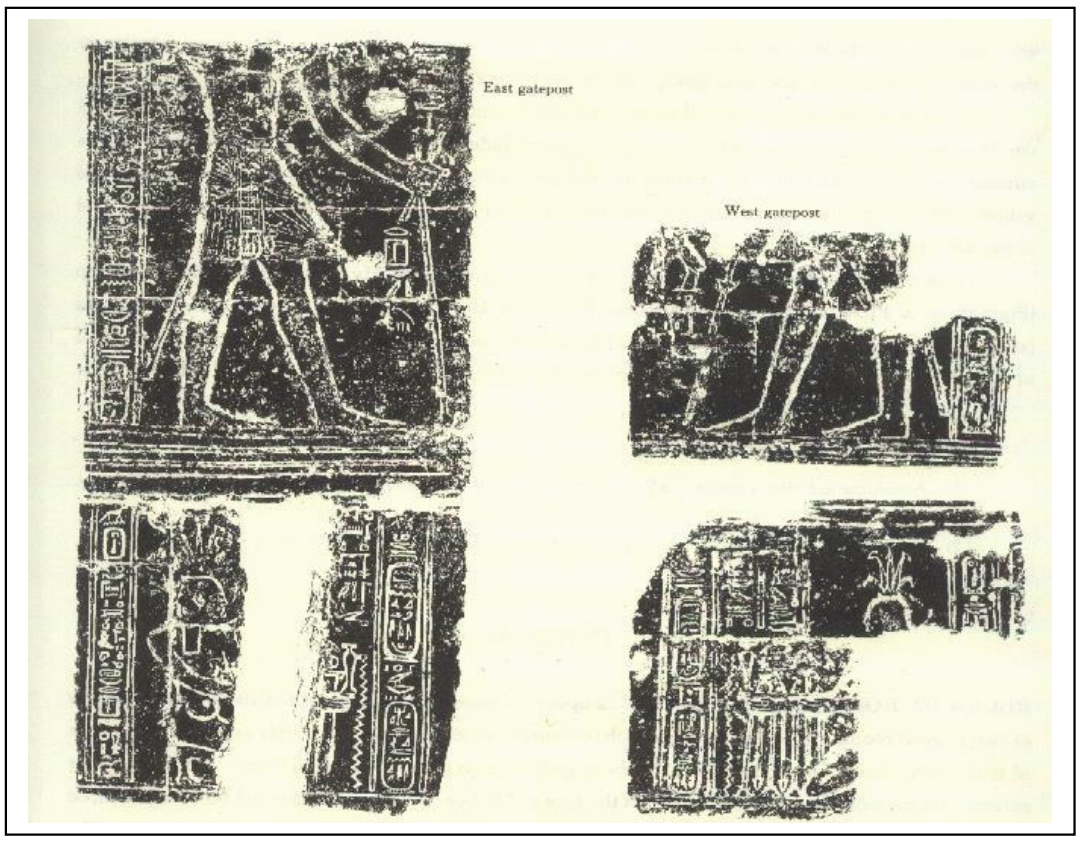

(شكل r أ ) رسم تخطيطي يوضح نقوش وزخارف مدخل صالة الأعمدة

نقلا عن : 17 


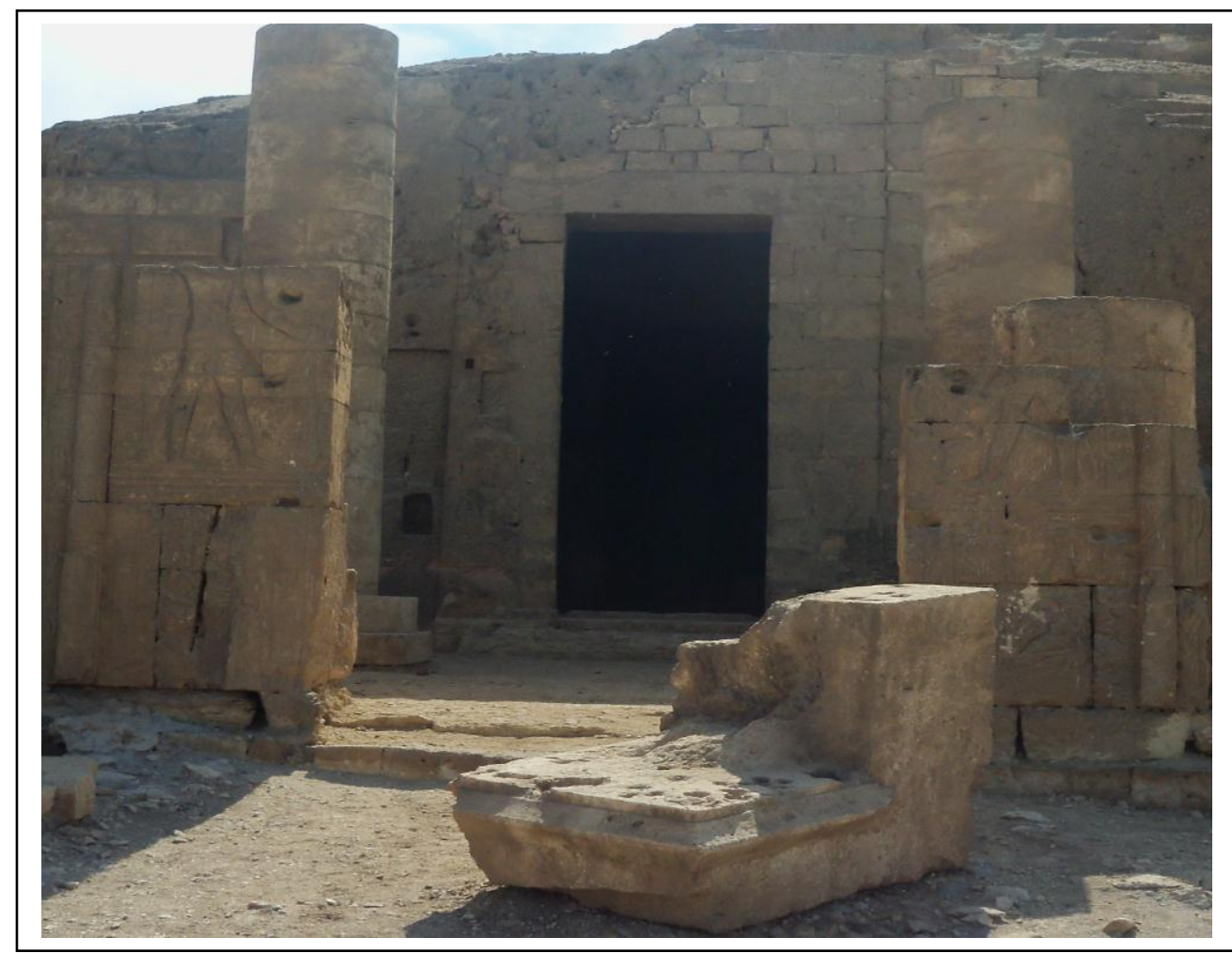

(شكل r ب ) مدخل صالة الأعمدة

(تصوير الباحث)

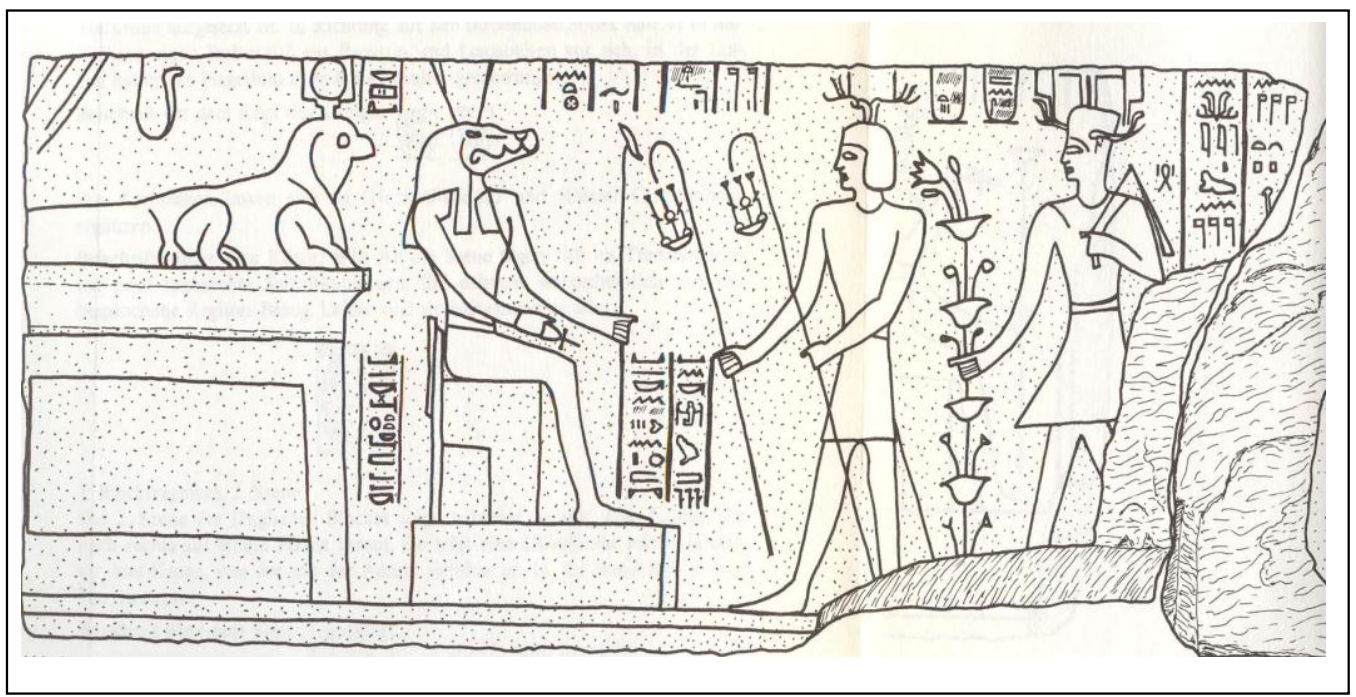

( شكل - r ) رسم تخطيطي يوضح الإمبراطور نيرون يقدم القرابين للمعبود سويك

نقلا عن :Kessler (D.),Op.Cit,P.360 


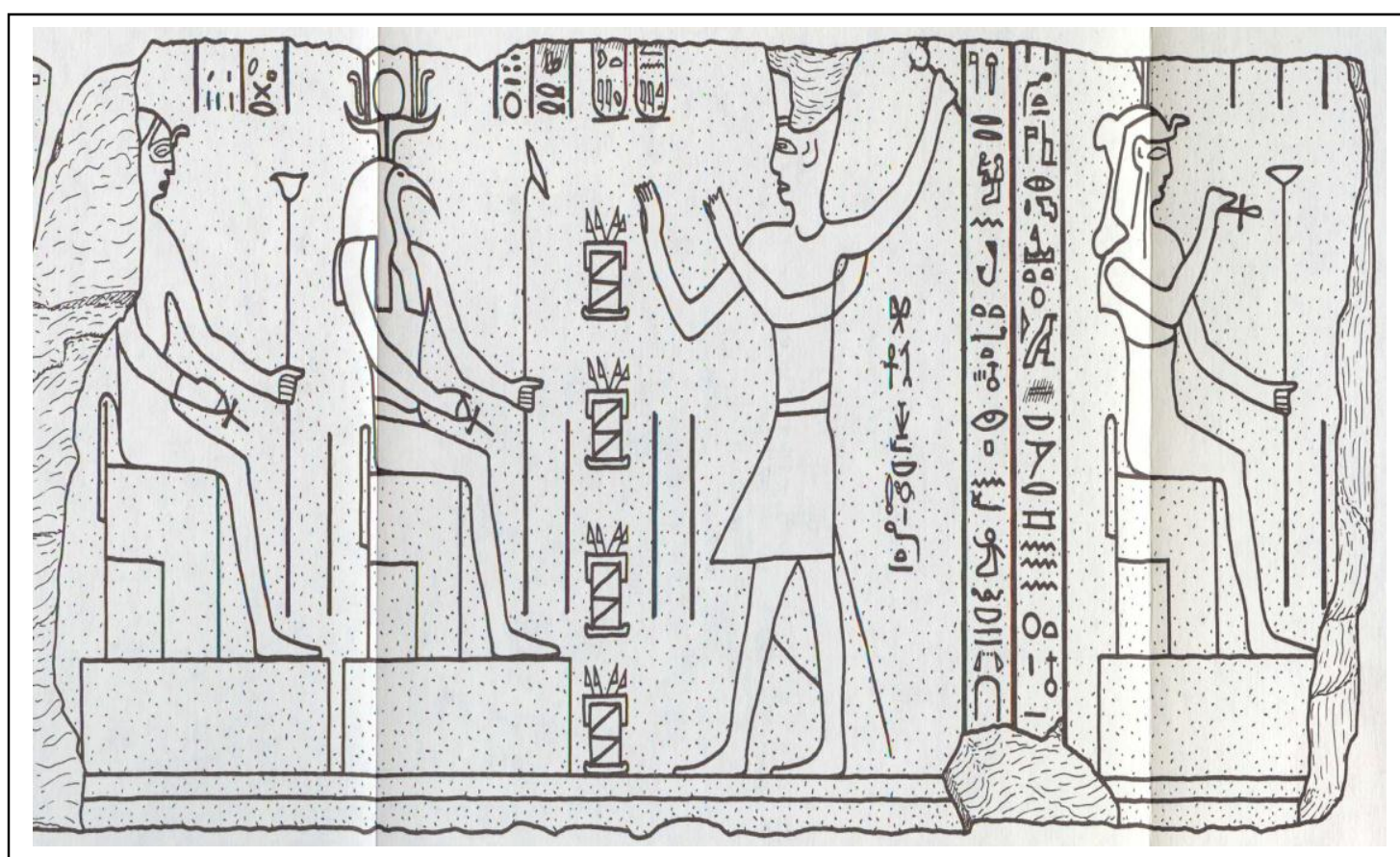

( شكل - ؛ ) رسم تخطيطي يوضح الإمبراطور نيرون يقدم قرابين صناديق المريت

نقلا عن :Kessler (D.),Op.Cit ,Fig .22

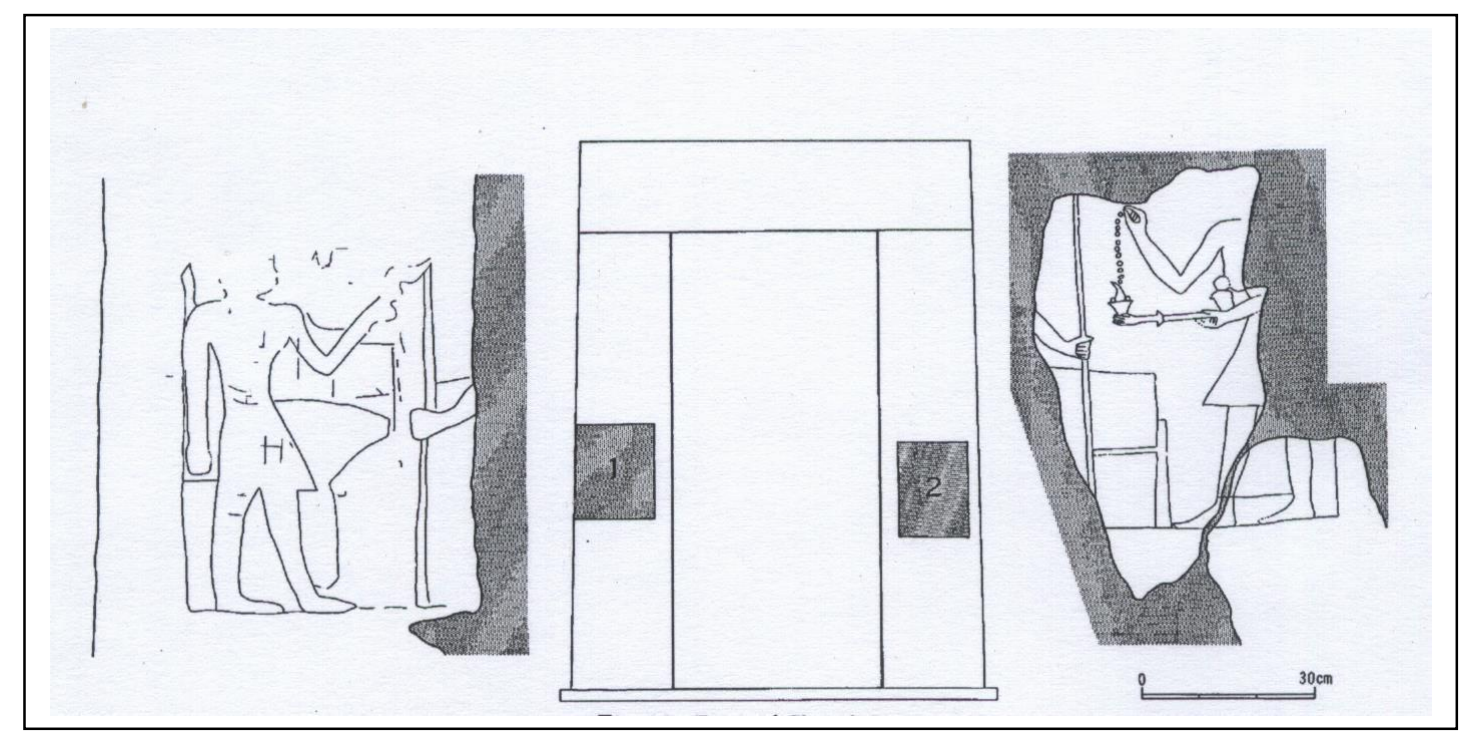

(شكل - ه ) بقايا النقوش الموجودة علي مدخل الحجرات الداخلية للمعبد

نقلا عن : 13 
(1) عرف هذا المعبد في تقرير البعثة اليابانية التي تعمل بالمدينة باسم " المعبد الغربي " ويعود ذلك إلي العثور

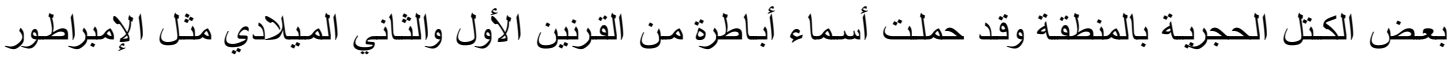

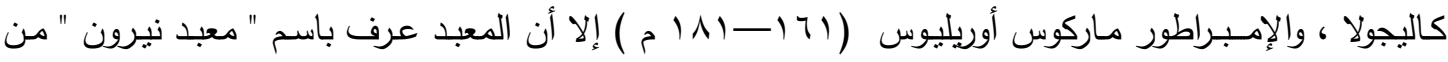

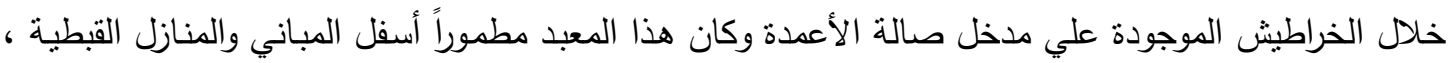

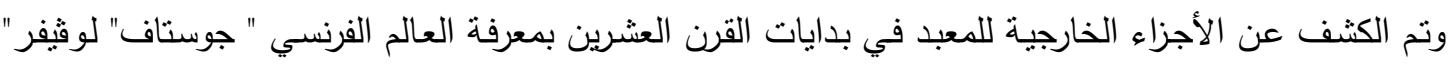

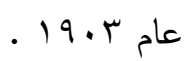

kawanishi (H.), Akoris, Report of The Excavation at Akoris in Middle Egypt ,1981-1992, Tsukuba ,Kyoto,1993,PP.11,34

( T)Kessler (D.),Historische Topographie der Region Zwischen Mallawi und Samaiut ,Wiesbaden ,1981,P.253.

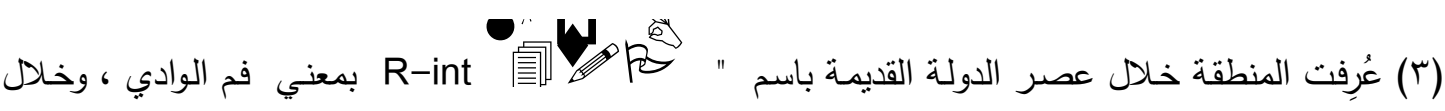
عصر الدولة الوسطي اسم "Mr-nfrt وتعني القناة الجميلة، وجاء اسمها في عصر الدولة الحديثة باسم

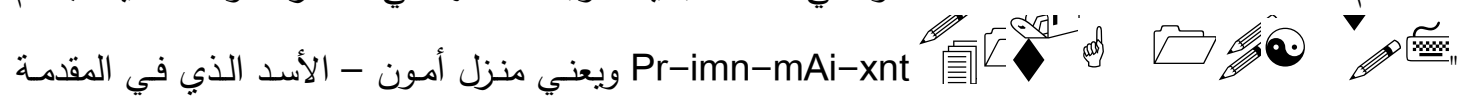
،وخلال العصرين اليوناني والروماني ، تتوعَّت الأسماء التي أطلقت علي المدينة خلال تلك الفترة ، فقد ذُكرت

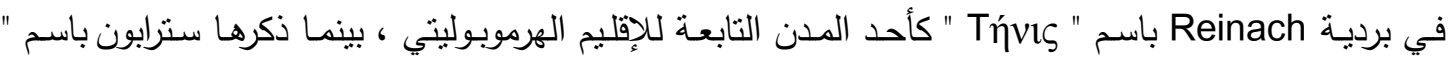

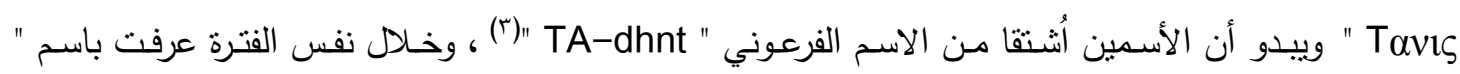

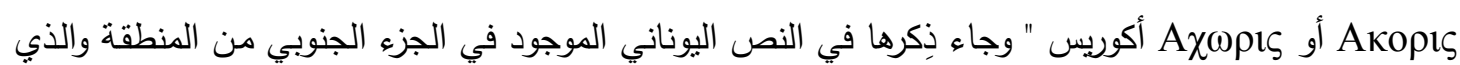

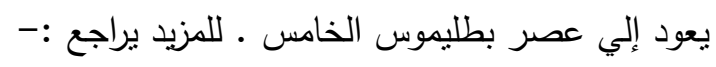

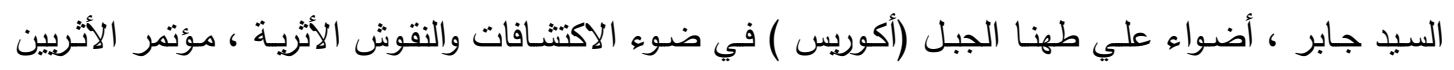

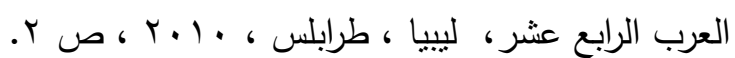

Gundlach (R.), Tehne (Akoris) in: $\boldsymbol{L} \ddot{\boldsymbol{A}} \boldsymbol{V I}$,1986,P.304.

Kessler (D.),Historische Topographie der Region Zwischen Mallawi und Samaiut ,Wiesbaden ,1981,P.253

Lefebvre (G.)\& Barry (L.), Rapport sur Les Fouilles Executées Á Tehnéh En 1903-1904 ,ASAE.6 ,1905,P.154.

(₹)Arnold (D.), Temples of The Last Pharaohs, Oxford University Press, 1999 ,P.265.

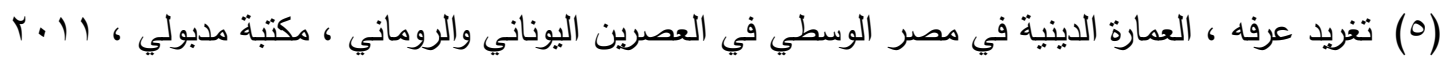

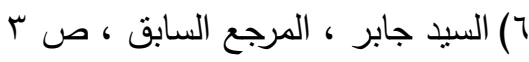

Wreszinski (W.),Bericht über die Photographische Expedition von Kairo bis Wadi Halfa $\left({ }^{\vee}\right)$ ,Max

Niemeyer Verlag ,1927,PP.28-29.

(^) طريقة أثـلر :- هي احدي طرق البنـاء القديمـة المستخدمة في إقامـة الجدران والحوائط ، وتتم من خـلال

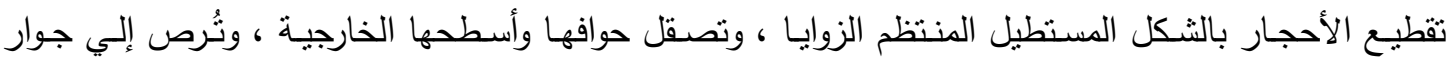


بعضها البعض لإقامة الجدار ، وتحتاج هذه الطريقة إلي أسلوب في وصل الكتل إلي جوار بعضها ويتم ذلك

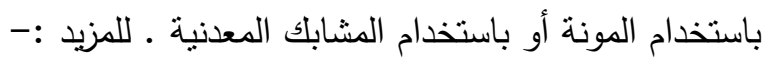

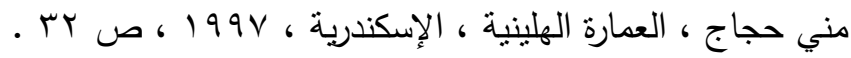
(9)Zayed(A.), The Antiquities of El- Minia ,Cairo ,1960,P.71.

(• (1) حلية الخيزرانة : الأصول المعمارية الأولي لحلية الخيرزانة ترجع إلي حزم سعف النخيل المنداخلة معاً علي شكل أربطة تمند علي أطراف الأكواخ والمباني لحمايتها من التآكل ، وعوامل التعرية ، وعندما قام التهام الفنان بتتفيذ وتقليد هذه الحلية في الحجر حرص على تصوير شكل الأربطة المتداخلة من خلا رسومات ورئل وخطوط

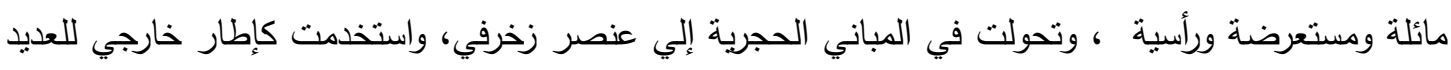

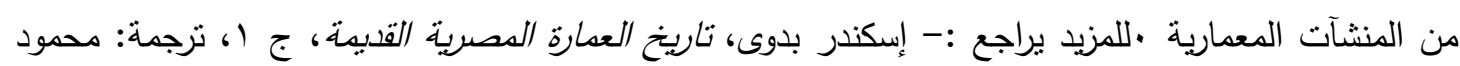

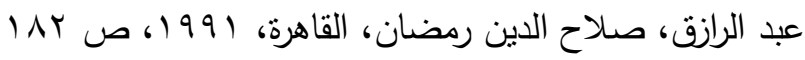

(11) Lefebvre (G.)\& Barry (L.), Op.Cit,P.146

( r)Beckerath( J.V), Handbuch Der Agyptischen Konigsnamen, Von Zabern,Mains ,1999,P.254. )( IrZayed(A.),Op.Cit,P.71.

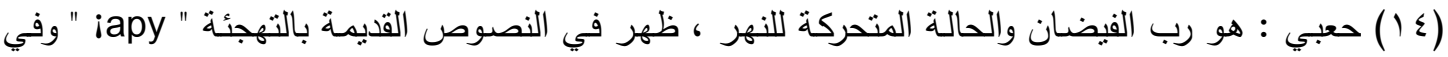

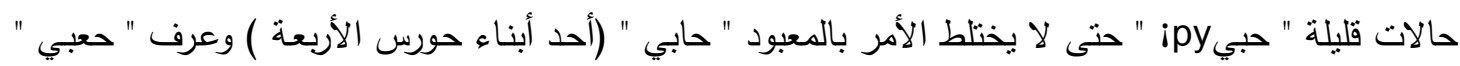

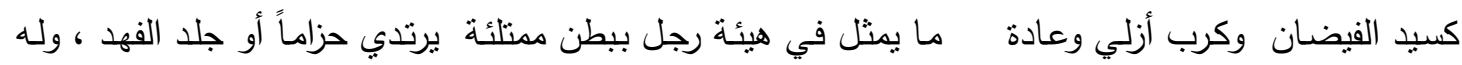

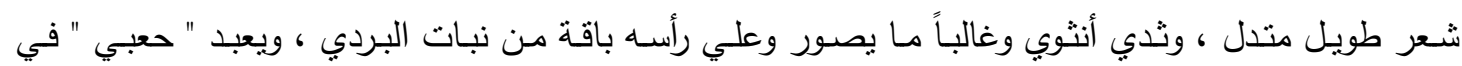

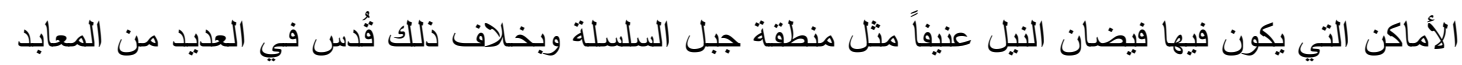

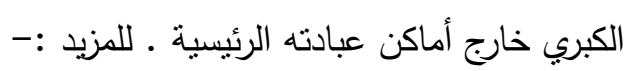

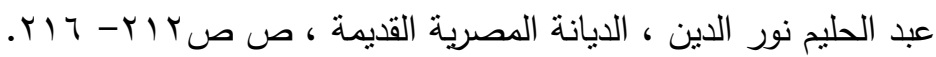

(10)Lefebvre ( G.)\& Barry(L.),Op.Cit,P.145.

( 1 7)Beckerath (J.V),Op.Cit,P.254.

( V)Zayed (A.), Op.Cit ,P.71.

( $/ \wedge) L e f e b v r e(G) \& B a r r y.(L),. O p . C i t, P .146$.

(9 (1) نتير العبارة إلي احدي مدن مصر العليا المرتبطة بالفيضـان ، ونظراً للارتباط بين المعبود " سوبك "

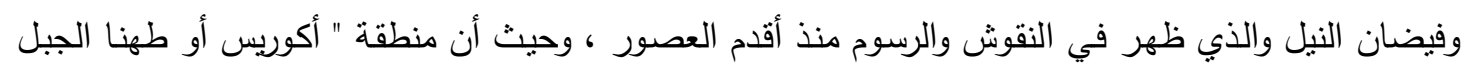

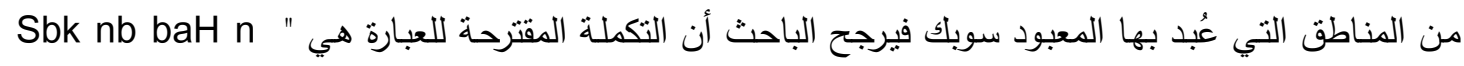

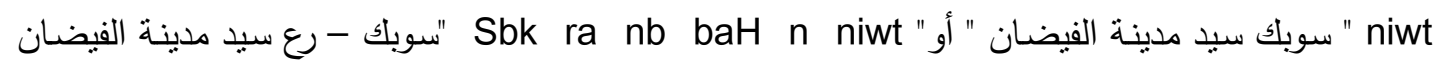
(الباحث)

Lefebvre (G.)\& Barry (L.) و Kessler (D.) تم تشجيل نقوش وزخارف هذا العتب بمعرفة ) (Y.) ويصعب حالياً التحقق من هذه الزخارف والنقوش نظراً لفقدها حالياً.

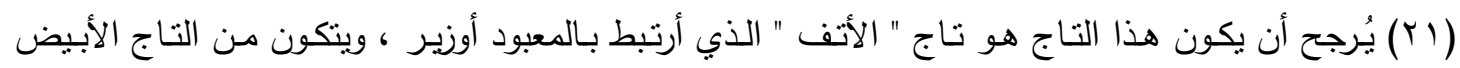

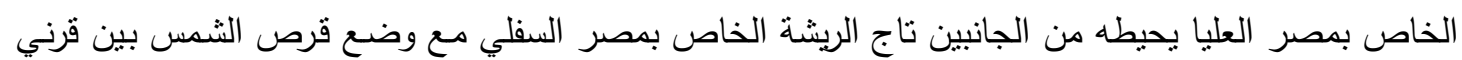

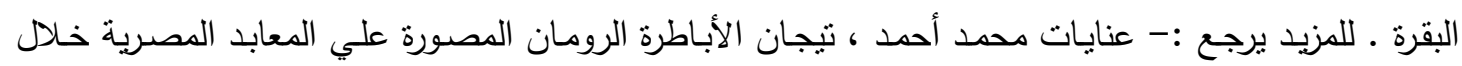

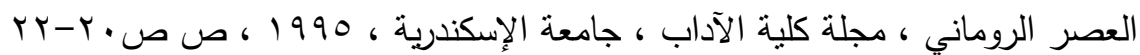


(Zayed (A.) ، Porter \& Moss ذأن هذا التصوير يمثل " كاهن " وهو ما لا يتفق معه الباحث حيث أن العلاقة بينالملك" والمعبود علاقة مباشرة ولا تحتاج إلي وسيط .

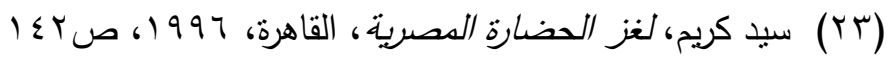
Wilson,(P.) , A Ptolemaic Lexicographical Study of the Texts in the Temple of Edfou, OLA 78, Leuven, 1997, P.156

(Y (Y) صولجان واس : يُمثل عصا الراعي أو العضو التتاسلي للثور ، ويعتقد أن الجزء السفلي منه يمثل رجلي حيوان، والجزء الأوسط يمثل الجسد وربما رقبة طويلة لزراف أو ما شابه، أما الرأس فهي لكلب أو ثعلب أو ربما

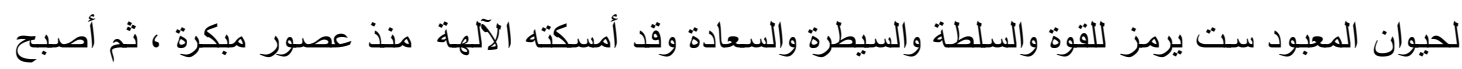

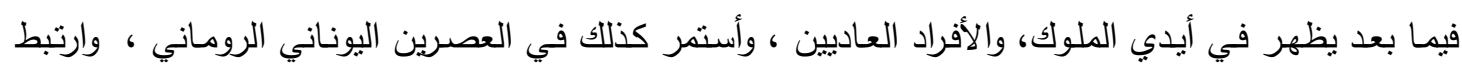
Karl Martin (G.),WAs- Zepter, $\boldsymbol{L} \ddot{A} \boldsymbol{V I}, 1986, P P .1152-1154$.

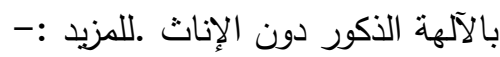
(Yo) ربما إنـارة إلي المعبود سوبك ، الذي صور بالمنظر ويعلو رأسه ريشنتين ، وقد جاء وصف سوبك في

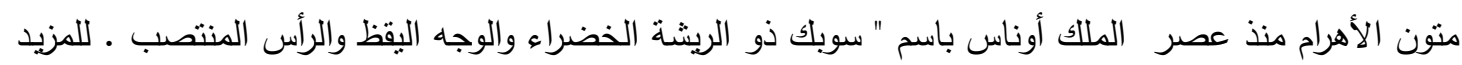

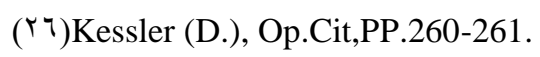

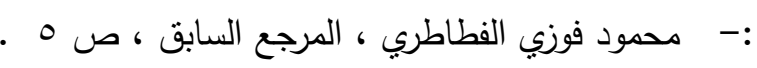

ترمز هذه الصناديق إلي البعث والخلود وهي عبارة عن أربعة صناديق تمنل الجهات الأصلية التي جابتها

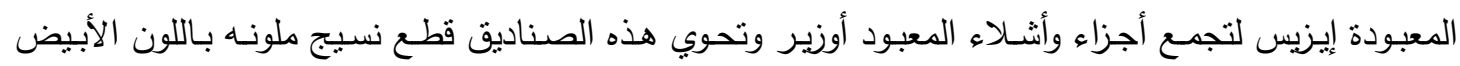
والأحمر والأحمر الفاتح والأحمر القاتم .للمزيد

يراجع :-سيلفي كوفيل ، قرابين الآلهة في مصر القديمة ، نرجمة ، سهير لطف الها ، بي إنترو ، القاهرة ،

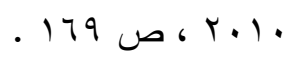

(Y^) يبدو أن الفنان هنا لم يكن لديه دراية كافية بالطقوس المتبعة عند تقديم هذه القرابين ، فحاول إحداث

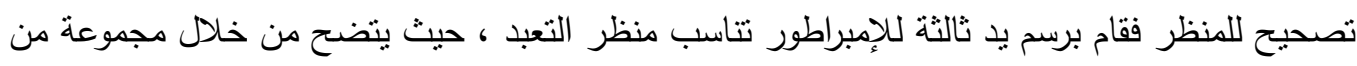

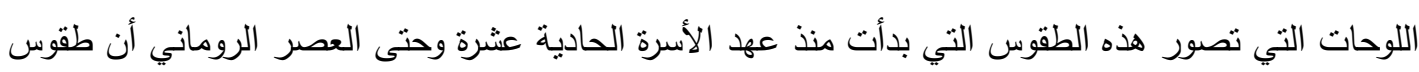
تقديم قرابين المريت لم تتغير ، فالملك برفع إحدى ذراعية للخلف مدسكا بصولجان القوة بينما ترتكز يده الثانية

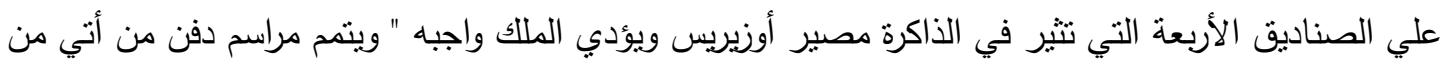

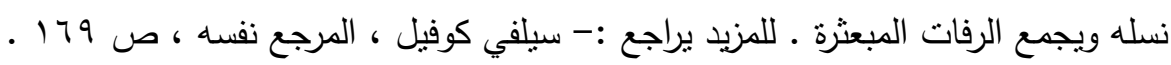

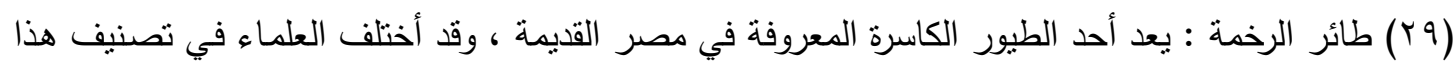

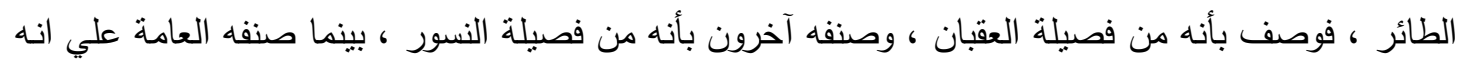

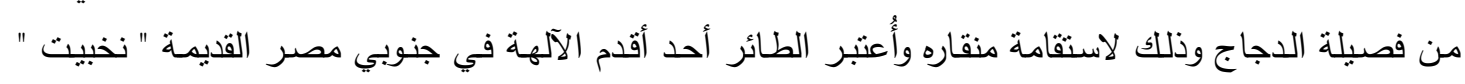
والتي كانت تعتبر حامية الفرعون، الملكيون ومصر ، وكانت تظهر دوما بجناحيها الممتدان دلالة على الحماية

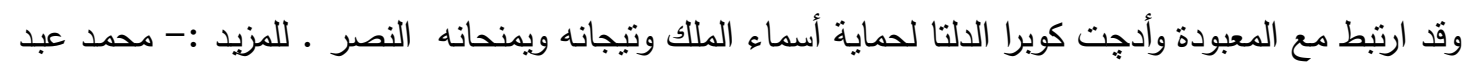

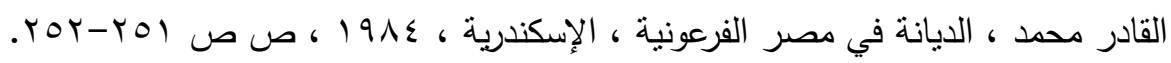

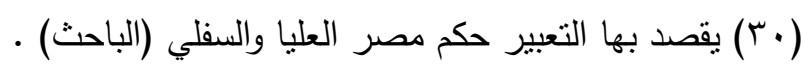
(1) ربما يقصد بهذا التعبير الحكم والسيطرة علي الإمبراطورية الرومانية (الباحث).

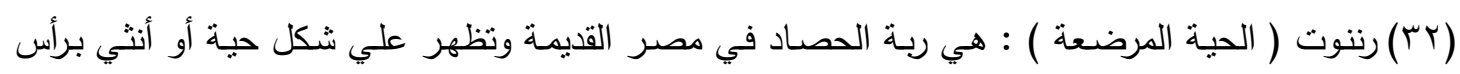
الكوبرا يعلو رأسها قرنان وقرص الثمس وريشتان ، عبدت كمعبودة حامية للغذاء والحصاد ووصفت بأنها المبه المربية 
المقسة وقدت خلال الدولة القديمة كحارسة وحامية للملك في حياته وبعد موته ـ للمزيد يراجع :- عبد الحليم

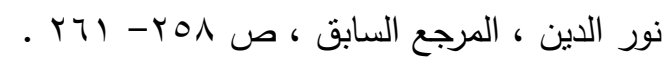

( ${ }^{\top}$ T)Kessler (D.),Op.Cit,P.260.

( $(\varepsilon)$ Lefebvre (G.)\&Barry (L.),Op.Cit,P.148.

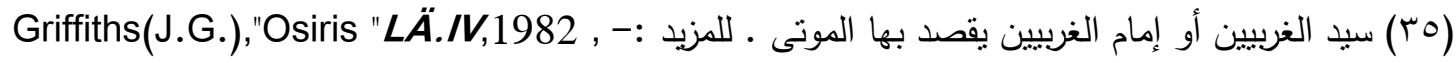
PP.623-631.

( آ؟) مر - نفرت ( القناة الجميلة ) هو الاسم الذي أطلق علي مدينة أكوريس (طهنا الجبل ) خلال عصر

( $\vee$ V Kawanishi (H.),Op.Cit,P.22.

· الدولة الوسطي

( $\wedge$ )Lefebvre (G.)\& Barry (L.),Op.Cit ,P.144.

( 9 q)Lefebvre (G.)\& Barry (L.),Op.Cit,P.144.

(๕•)Kawanishi (H.),Op.Cit,P.20

(₹) Wilson (P.), Op.Cit,P.131.

(Y (؟ُعد طقس حرق البخور من الطقوس الهامـة التي كانت تتم ضمن شعائر الخدمة في المعابد المصرية

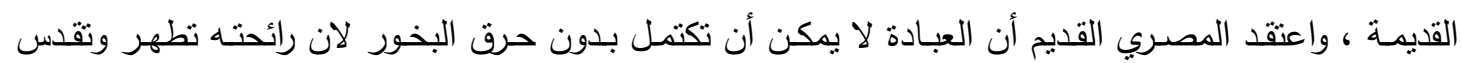

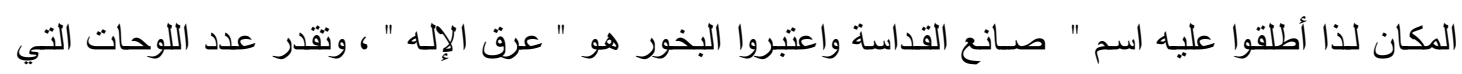

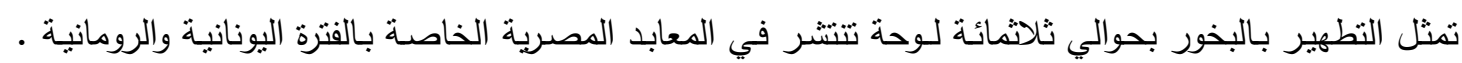

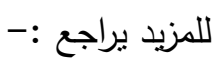

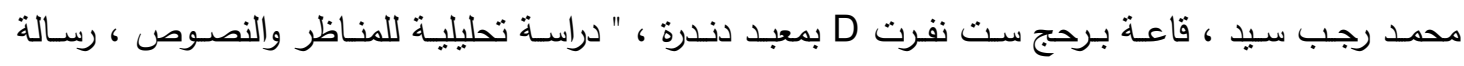

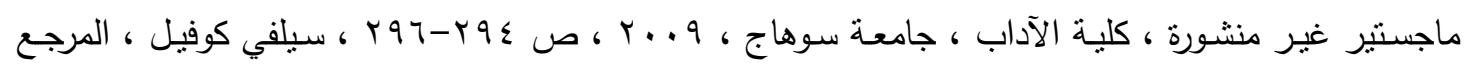

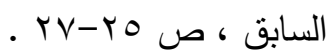

Kawanishi (H.) ,Op.Cit,P.326-329.

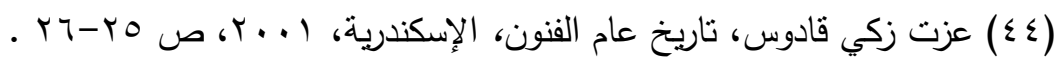

Kessler(D.),Op.Cit,P.260.

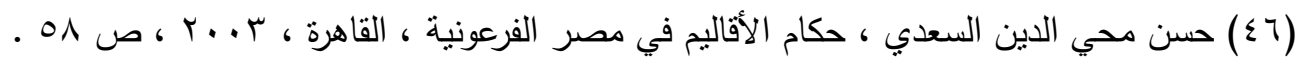

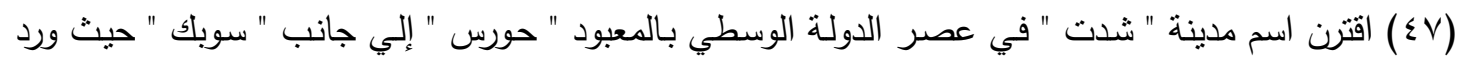

$$
\begin{aligned}
& \text { اسم هذين المعبودين بمنطقة الفيوم تحت اسم " سوبك سيد شدت وحورس القاطن في شدت " ـ للمزيد يراجع :- } \\
& \text { محمود فوزي الفطاطري ، المرجع السابق، ص هنودين } 9
\end{aligned}
$$

Kessler (H.),Op.Cit,P.261.

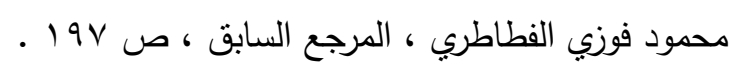

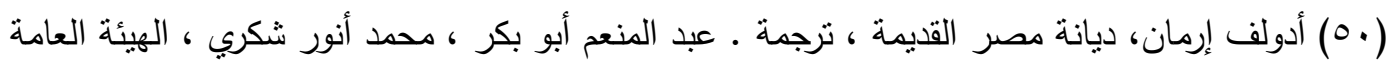

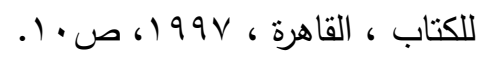

